\title{
ISOLATION AND IDENTIFICATION OF ALKALOIDS EXTRACTED FROM DAYAK ONION (Eleutherinae palmifolia (L.) Merr)
}

\author{
S. M. Sinaga ${ }^{1, *}$, M. Nainggolan ${ }^{2}$ and Iksen $^{3}$ \\ ${ }^{1}$ Department of Pharmaceutical Chemistry, Faculty of Pharmacy, Universitas Sumatera Utara, \\ Medan-20155, Indonesia \\ ${ }^{2}$ Department of Biological Pharmacy, Faculty of Pharmacy, Universitas Sumatera Utara, \\ Medan-20155, Indonesia \\ ${ }^{3}$ Department of Pharmacy, Sekolah Tinggi Ilmu Kesehatan Senior Medan, \\ Medan-20141, Indonesia \\ *E-mail: sitimorinsinaga28@gmail.com
}

\begin{abstract}
Dayak onion (Eleutherine palmifolia (L.) Merr.) is one plant that can cure various diseases and symptoms such as constipation, dysuria, cancer, dysentery, ulcers, diabetes mellitus, hypertension, antihypercholesterol, antimelanogenesis and antioxidant. However, there is no report about the chemical composition and their isolation. The purpose of this research is to extract and isolate the alkaloid compounds from Dayak onion and to identify the alkaloids by UV and FTIR spectrophotometer.TLC of alkaloid extracts from the plants used in this study revealed the presence of these compounds by using Bouchardat's reagent to reveal characteristic orange bands of alkaloids. From the data obtained, The isolation of the crude alkaloid extract obtained two pure isolates, they are isolated A $(\mathrm{Rf}=0.51)$ and isolate $\mathrm{B}(\mathrm{Rf}=0.57)$. Isolate $\mathrm{A}$ gives a maximum absorbance at $270 \mathrm{~nm}$ wavelength and isolate $\mathrm{B}$ at $271 \mathrm{~nm}$. The results of FTIR showed the presence of aliphatic $\mathrm{CH}, \mathrm{CH}_{2}, \mathrm{C}=\mathrm{O}, \mathrm{C}=\mathrm{C}, \mathrm{C}-\mathrm{N}, \mathrm{C}-\mathrm{O}$ for isolate A and aliphatic $\mathrm{CH}, \mathrm{CH}_{2}, \mathrm{CH}_{3}, \mathrm{C}=\mathrm{C}, \mathrm{C}-\mathrm{N}, \mathrm{C}-\mathrm{O}$ for isolate B.Based on the above results, it can be concluded that Dayak onion has a potential of alkaloids constituents for further study.
\end{abstract}

Keywords: Dayak Onion, Extract, TLC, UV, IR, Alkaloids

(C) RASĀYAN. All rights reserved

\section{INTRODUCTION}

The use of plants as medicine is an ancestral heritage since immemorial time and has been used for quite a long time in almost all countries in the world. Indonesia is one of the countries producing medicinal plants that have the potential for biodiversity. Efforts to search for medicinal plants have long been carried out, both to find new compounds or to add to the diversity of existing compounds. The search was carried out with various approaches such as empirical, ethnobotany, and ethnopharmacology. Then an attempt was made to isolate pure compounds and their derivatives as the basic ingredients of modern medicine or making extracts for phytopharmaca drugs. ${ }^{1}$

One of the plants that can be used as medicine is Dayak onion (Eleutherine palmifolia (L.) Merr.), which are included as terna plants, with a height of $25-50 \mathrm{~cm}$, white flowers, red tier tubers. ${ }^{2}$ This plant contains active chemical compounds in the form of alkaloids, flavonoids, steroids, glycosides and phenolics. ${ }^{3}$ The bulb of Dayak onion has been reported to have several bioactivities, including antiacne, ${ }^{4}$ antibacterial, ${ }^{5,6}$ antimitotic, ${ }^{7}$ antifungal, ${ }^{8}$ and also antioxidants. ${ }^{9,10}$

Many alkaloid compounds have prominent physiological activities that are widely used in the field of medicine. ${ }^{11}$ These active compounds can act as analgesics, sedatives, bioinsecticides, stimulants on autonomic nerves, malaria drugs, cancer drugs, ${ }^{12-13}$ anti-inflammatory, antidiabetic and diuretic. ${ }^{14}$ Isolation is a mandatory step of determining and characterizing pure alkaloids. As the target pure

Rasayan J. Chem., 12(3), 1298-1303(2019)

http://dx.doi.org/10.31788/RJC.2019.1235243

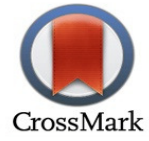


alkaloids vary in polarity and thermal stability, a combination of conventional TLC methods and instrumentation technologies (IR dan UV.) are commonly used to ensure efficient isolation process. The aim of this study is to isolate and determine the alkaloids compound from the Dayak onion.

\section{Plant Collection and Identification}

\section{EXPERIMENTAL}

The Dayak onion was collected from Tuntungan district of Medan (Indonesia). The specimen of the plant was identified and authenticated by the Indonesian Institute of Science-Research Center for Biology (Cibinong, Indonesia; No: 367/IPH.1.02/If.8/III/2010). Fresh Dayak onions were dried in the open air without exposure to direct sunlight and then the dried sample was powdered by mechanical milled.

\section{Extraction and Isolation of Alkaloids}

About $1.3 \mathrm{~kg}$ of the fine powder plant sample was extracted with $80 \%$ ethanol by using maceration for 5 days at room temperature. ${ }^{15-18}$ The extract was made alkaline with strong ammonia ( $\mathrm{pH}$ around 9-10) The solution was extracted with chloroform and washed with distilled water. The chloroform solution part then added with $\mathrm{HCl} 2 \mathrm{~N}$ and then separated for three times. The chloroform solution part was evaporated by using rotary evaporator to get the crude extract of alkaloids.

\section{Detection of Alkaloids using Thin Layer Chromatography (TLC)}

Thin Layer chromatography was used for preliminary detection of alkaloids. It was also for testing and selecting the right solvent system for chromatography. Silica gel $\mathrm{GF}_{254}$ precoated in TLC plate was used as a stationary phase with toluene: ethyl acetate (9:1) as mobile phase (Skripsi). After the plate developed, it was put to dry at room temperature and then spray with Bouchardat's reagent to detect and visualized the spot which is active with the reagent. The spot color that occurs was observed and calculated the values of the $\mathrm{Rf}^{19,20}$

\section{Detection of Alkaloids Using UV Spectrophotometer}

Identification of isolates by using UV spectrophotometer was carried out by dissolving the isolates with chloroform then measuring its absorbance at a wavelength of $200-400 \mathrm{~nm}$.

\section{Detection of Alkaloids Using FTIR}

Identification of isolates by using FTIR was carried out by mixing isolates with potassium bromide using a mixture vibrate tool and then printing it into pellets and inserted into the FTIR, then measured the absorbance at a frequency of $4000-500 \mathrm{~cm}^{-1}$

\section{Thin-Layer Chromatography (TLC) Study}

\section{RESULTS AND DISCUSSION}

TLC results of alkaloids showed that five orange bands were observed for Dayak onion. The presence of alkaloids from these compounds were revealed by using the Bouchardat's reagent and the Rf values for each spot were recorded (Fig.-1).Separation of crude alkaloid extract with preparative TLC using the benzene-ethyl acetate (9:1), toluene-ethylacetate (9:1) and chloroform-methanol-ammonia (85:15:1), as mobile phase. The results obtained from the best mobile phase are toluene-ethylacetate (9:1) which gives the most stain bands by using the Bouchardat spotting reagent. The result was obtained 5 bands on the TLC plate measuring $20 \times 20 \mathrm{~cm}$ after being sprayed with Bouchardat spotting reagent. Then the plate was removed from the vessel and dried, then the tip of the plate was sprayed with Bouchardat reagent. The silica plate part which gives the Rf values is the same as the positive stain on the Bouchardat reagent, then eluted with methanol solvent, the filtrate is evaporated and put in the refrigerator. The obtained crystal is purified by repeated washing using cold methanol to obtain a needle-shaped crystal. The results of the separation obtained a little amount of 1,2 and 5 bands so that the next analysis was only carried out on bands 3 and 4 .

Against bands 3 and 4, the purity test with one-way TLC is performed again using various mobile phases, namelyn-hexane-ethylacetate (9:1), toluene-ethylacetate (9:1), and chloroform-methanol-ammonia 
(85:15:1). The result turned out to still give an orange spot with a Bouchardat spotting appearance, while the $\mathrm{Rf}$ values were obtained respectively $0.34,0.51,0.86$ (band 3 hereinafter referred to as isolate A) and 0.41, 0.6, 0.9 (band 4 hereinafter referred to as isolate B) (Fig.-2 and 3). Furthermore, two-way TLC was carried out with the mobile phase toluene-ethyl acetate (9:1) giving one spot with Rf 0.51 (isolate A) and 0.57 (isolate B).

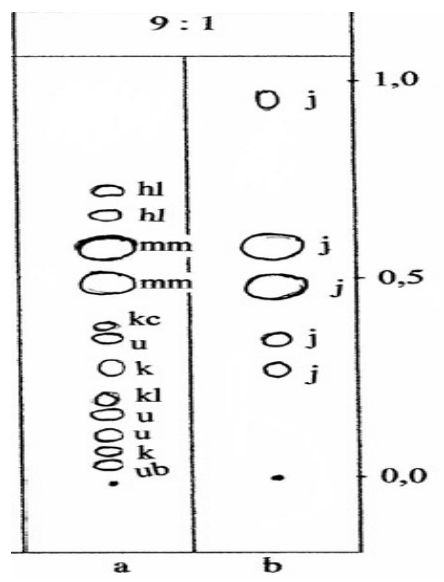

Fig.-1: TLC of Alkaloids by Using Toluene-Ethyl acetate (9:1) as Mobile Phase a: Visual; b: After sprayed by Bouchardat reagent; $\mathrm{j}$ : orange

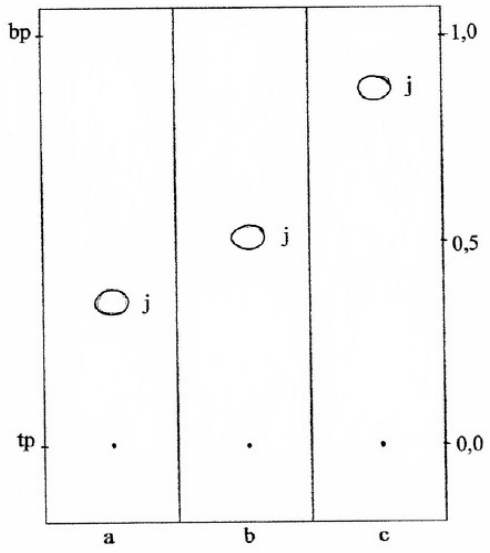

Fig.-2: TLC Result for Isolate A

a: Hexane:Ethyl Acetate (9:1); b: Toluene-Ethyl Acetate (9:1);

c: Chloroform-Methanol-Ammonia (85:15:1); j: Orange Color

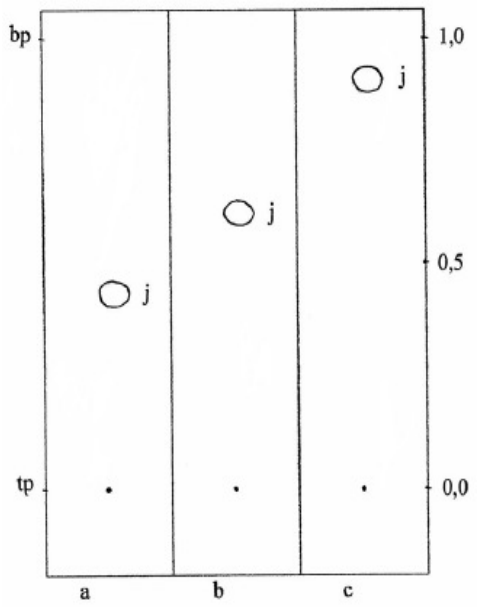

Fig.-3: TLC result for Isolate B

a: Hexane:Ethyl Acetate (9:1); b: Toluene-Ethyl Acetate (9:1); c: Chloroform-Methanol-Ammonia (85:15:1); j: Orange Color 


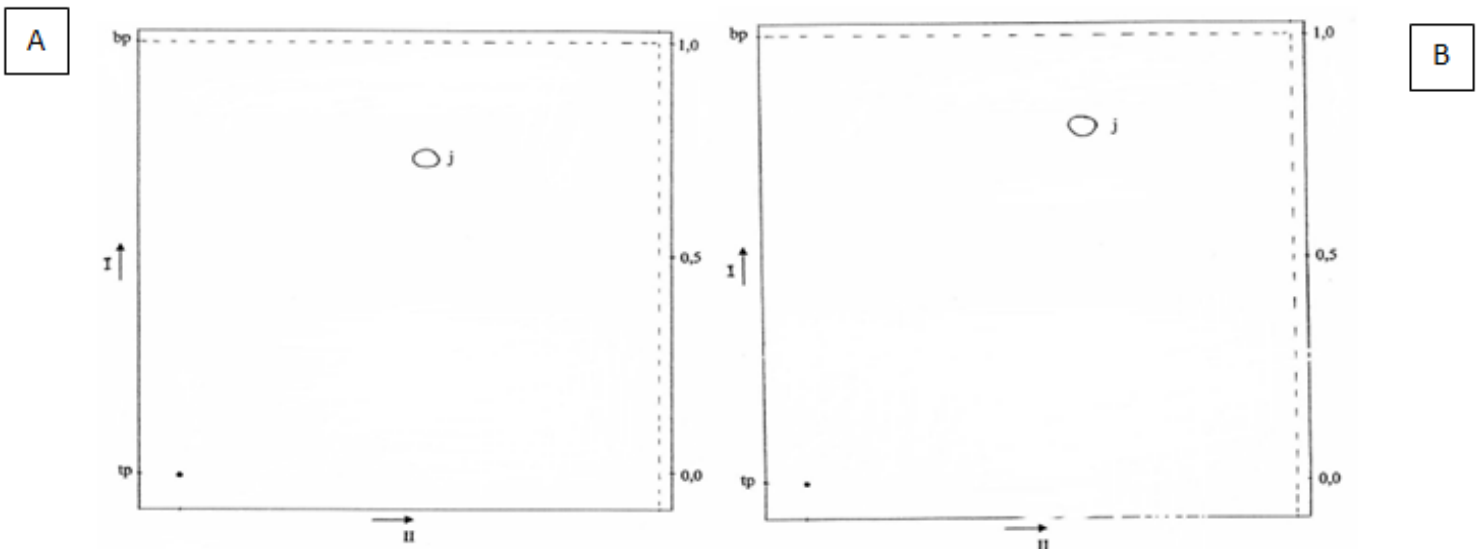

Fig.-4: Chromatogram Results of Two Way TLC From Isolate A and B

A: Isolate A; B: Isolate B; j: Orange Color

\section{UV and FTIR Study}

UV spectrophotometric results from isolates A and give maximum absorbance at the wavelength ( $\lambda$ ) 270 $\mathrm{nm}$ (isolate A) and $271 \mathrm{~nm}$ (isolate B). This indicates the presence of a chromophore group experiencing a transition $n \rightarrow n^{*}$ (Fig.-5 and 6). The results of FTIR from isolating A showed the presence of an aliphatic $\mathrm{C}-\mathrm{H}$ bond shown by two sharp peaks adjacent to the wavenumber $2,922.16 \mathrm{~cm}^{-1}$ and $2,850.79 \mathrm{~cm}^{-1}$, this is reinforced by the presence of a peak at wavenumber $1,462.04 \mathrm{~cm}^{-1}$ indicating the presence of a methylene group $\left(\mathrm{CH}_{2}\right)$. The weak peak at wavenumber $1,724.36 \mathrm{~cm}^{-1}$ indicates the presence of a $\mathrm{C}=\mathrm{O}$ group of esters. A sharp peak at wave number $1,587.42 \mathrm{~cm}^{-1}$ indicates the presence of a $\mathrm{C}=\mathrm{C}$ group. The moderate peak at wave number $1,355.96 \mathrm{~cm}^{-1}$ indicates the presence of a $\mathrm{C}-\mathrm{N}$ group. The peak at wave number $1,097.50 \mathrm{~cm}^{-1}$ indicates the presence of a $\mathrm{C}-\mathrm{O}$ group. In the spectrum, there is no peak N-H at wavenumber around $3500 \mathrm{~cm}^{-1}$ so it is suspected that the alkaloid in isolate A is a tertiary amine compound (Fig.-7).

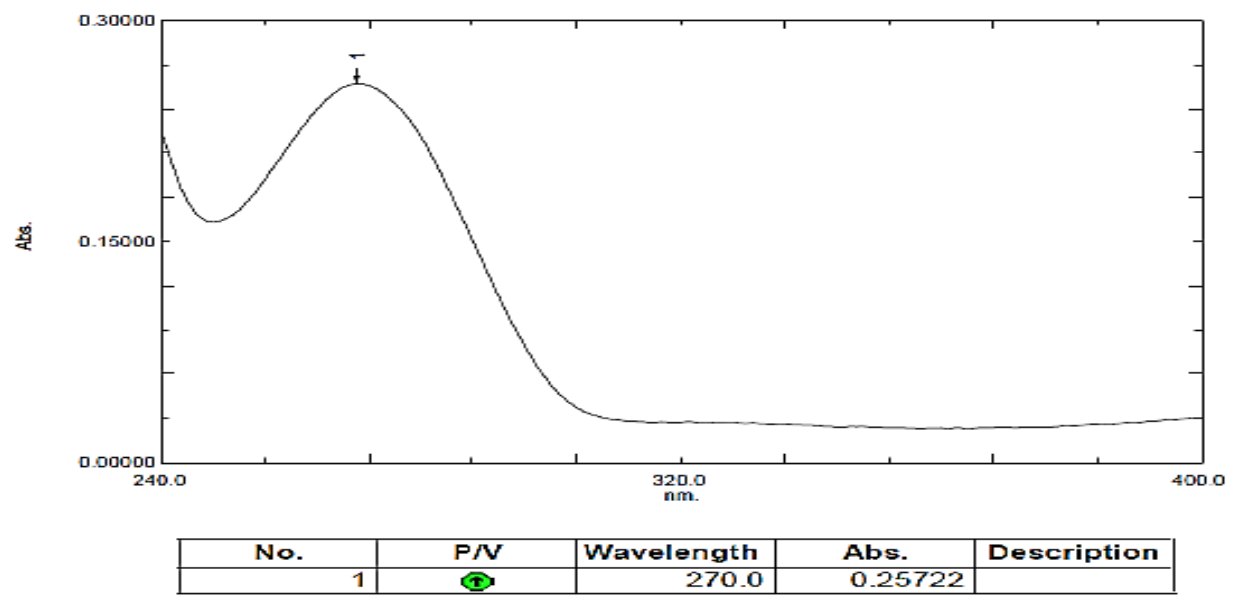

Fig.-5: UV Spectrum of Isolate A

The results of FTIR from isolate B showed the presence of an aliphatic $\mathrm{CH}$ bond shown by two peaks which are adjacent to the wave number $2,922.16 \mathrm{~cm}^{-1}$ and $2,852.72 \mathrm{~cm}^{-1}$, this is reinforced by the presence of a sharp peak at wave number $1,462.04 \mathrm{~cm}^{-1}$ which shows the presence of a methylene group $(\mathrm{CH} 2)$ and the presence of a peak at wave number $1,379.10 \mathrm{~cm}^{-1}$ indicates the presence of a methyl group (CH3). The moderate peak at wave number $1,589.34 \mathrm{~cm}^{-1}$ indicates the presence of a $\mathrm{C}=\mathrm{C}$ group. Moderate peak at wave number $1,355.96 \mathrm{~cm}^{-1}$ indicates the presence of a $\mathrm{C}-\mathrm{N}$ group. The peak at wave number $1,097.50 \mathrm{~cm}^{-1}$ indicates the presence of a $\mathrm{C}-\mathrm{O}$ group from the ether. In the spectrum there was no peak $\mathrm{N}-\mathrm{H}$ at wave number around $3,500 \mathrm{~cm}^{-1}$ so it was assumed that the alkaloid in isolate B was a tertiary amine compound (Fig.-8). 
RASĀYAN J. Chem.

Vol. 12 | No. 3 |1298 - 1303| July - September | 2019

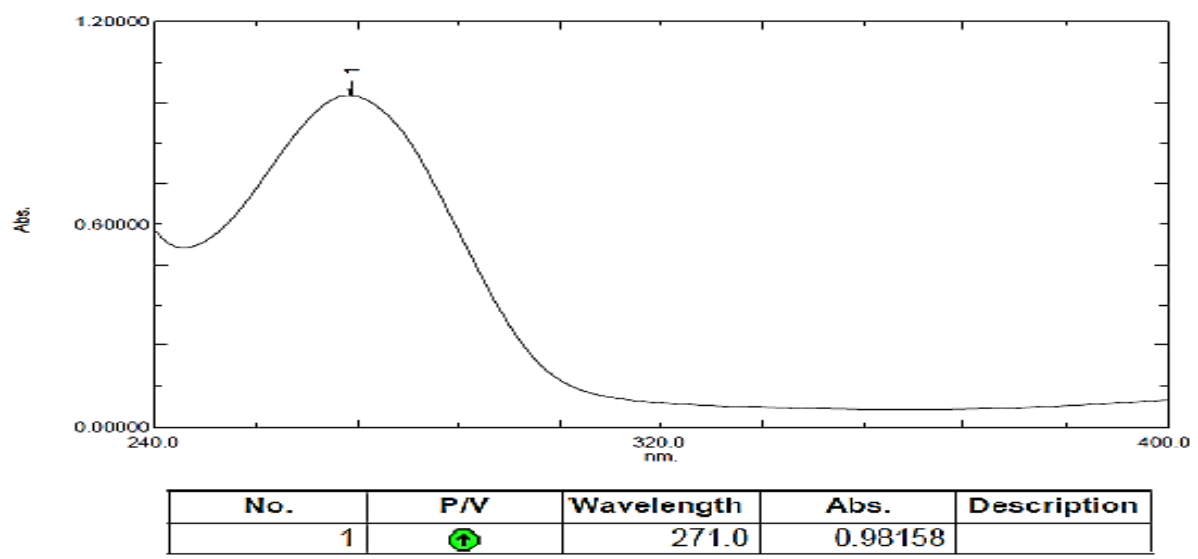

Fig.-6: UV Spectrum of Isolate B

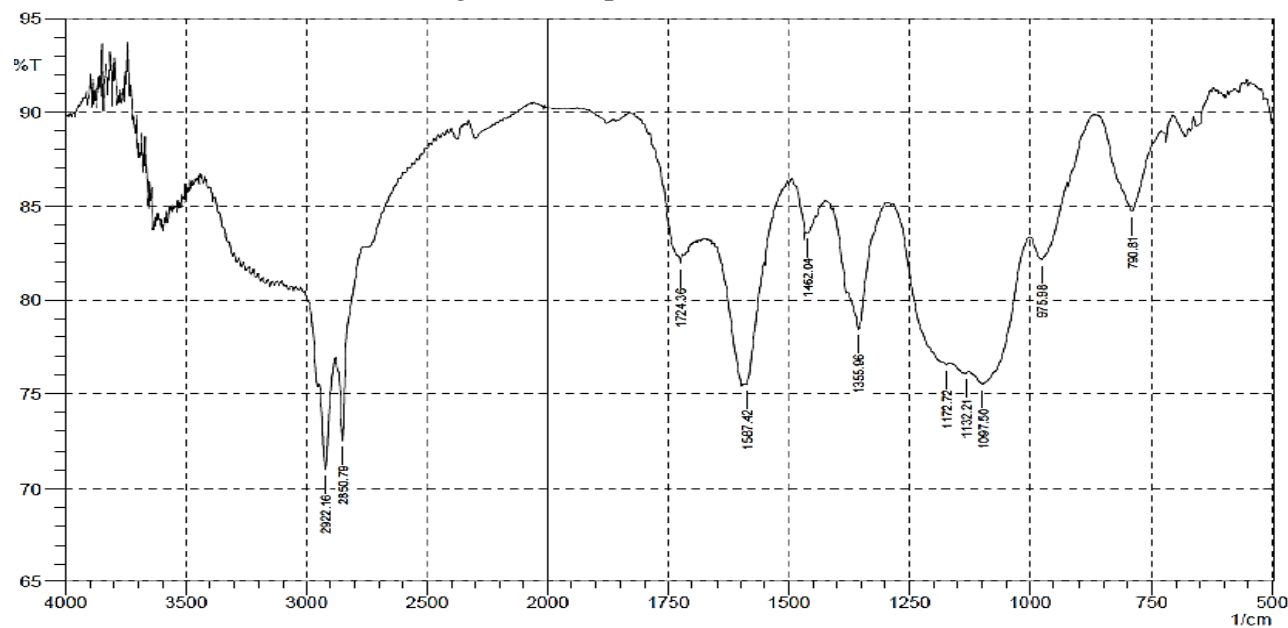

Fig.-7: FTIR Spectrum of Isolate A

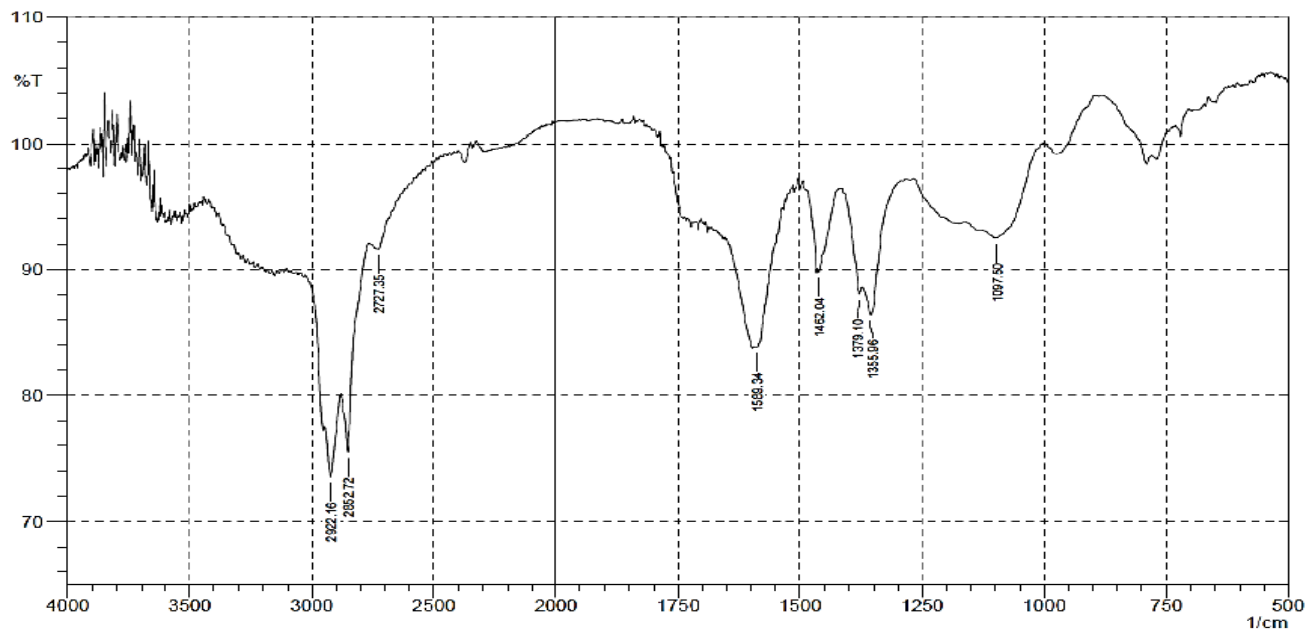

Fig.-8: FTIR Spectrum of Isolate B

CONCLUSION

In summary, this is the first report that described the isolation and identification of alkaloids extracts from Dayak onion (Eleutherine palmifolia (L.). Alkaloids extracted from these plants identified important compounds which may be used to develop more biopharmaceuticals product that has benefits for human. The next study will be using NMR and MS to determine the structure of these isolates and examine their pharmacology activities such as anticancer. 


\section{ACKNOWLEDGMENT}

All the authors acknowledge the assistance and support provided by D.M Purba and Universitas Sumatera Utara.

\section{REFERENCES}

1. H. Hernani, E. Djauhariya, Gulma Berkhasiat Obat, Penebar Swadaya, Jakarta, p. 1-3 (2004).

2. Y. Ogata, Indeks Tumbuh Tumbuhan Obat di Indonesia, PT Eisei Indonesia, Jakarta, p. 286 (2004).

3. V. Mierza, D. Suryanto, M.P. Nasution. Proceedings of the National Biology Seminar: Enhancing the Role of Biology in Creating National Achievement with Global Reach,340 (2011).

4. E.S. Syamsul, S. Supomo, H. Wijaya, B.A. Nugroho, T. Med. J., 20(3), 149(2015), DOI: 10.22146/tradmedj.8860.

5. E.T. Arung, I.W. Kusuma, E.O. Christy, K.Shimizu, R. Kondo, J. Nat. Med.,63, 473(2009), DOI: 10.1007/s11418-009-0351-7.

6. I.A. Wicaksono, D. Runadi, I. Firmansyah, National Journal of Physiology, Pharmacy and Pharmacology, 8(5), 741(2018).

7. A. Efendi, I. Ahmad, A. Ibrahim, Jurnal Sains dan Kesehatan,,1(3), 99(2015).

8. N. Diana, S. Khotimah, M. Mukarlina, J. Protobiont., 3(2), 225(2014).

9. A.M. Nur. Thesis, Faculty of Agricultural Technology, Bogor Agricultural University, Bogor, West Java, Indonesia (2011).

10. E.M. Kuntorini, M. Dewi, M. Misrina. Biodiversitas., 17(1), 229(2016), DOI: 10.13057/biodiv/d170133

11. J.B. Harbone, 1998, Phytochemical methods, in: A Guide to Modern Techinuqes of Plant Analysis, $3^{\text {rd }}$ ed.: Chapman and Hall, London.

12. M.M Cowan, Clinical Microbiology Reviews, 12(4), 564(1999).

13. T. H. Tjay, K. Rahardja, 2002, Obat-Obat Penting, $5^{\text {th }}$ ed.: PT Gramedia, Jakarta.

14. B. Dineshkumar, M. Mahadevappa, A. Mitra,International Journal of Phytomedicine, 2, 22(2010).

15. G. Haro, I. Iksen, R.M. Rumanti, N. Marbun, R.P. Sari, R.P.J. Gultom, Rasayan J. Chem., 11(1), 232 (2018), DOI: $10.7324 /$ RJC.2018.1112011.

16. S.M. Sinaga, S. Sudarmi, I. Iksen, K. Kevin, M.P. Sari, Rasayan J. Chem., 11(4), 1604 (2018), DOI: 10.31788/RJC.2018.1144067.

17. P. Raji, A.V. Samrot, D.B. Rohan, M.D. Kumar, R. Geetika, V.K. Sharma, D. Keethana, Rasayan J. Chem., 12(1), 123 (2019), DOI: 10.31788/RJC.2018.1144067.

18. M.R. Ahmed, V.G. Sastry, N. Bano, S. Ravichandra, M. Raghavendra, Rasayan J. Chem., 4(2), 289 (2011).

19. A.M.M. Shami, Ann. Chromatogr. Sep. Tech., 2(1), 1016 (2016).

20. N. Smita, M. Sushma, International Journal of Pharmacy and Pharmaceutical Sciences, 2, 150 (2010), DOI:10.22159/ijpps.2019v11i6.30805.

[RJC-5243/2019] 